\title{
The Analytical Approaches and Principles Used for the Purchases of Light Weight and Passenger Vehicles in a Saturated Market
}

\author{
Aleksey Solntsev ${ }^{1 *}$, Valeriy Zenchenko ${ }^{1}$, Vitaly Guliy ${ }^{1}$, Oyifien Ozaka Francis ${ }^{2}$, Viacheslav \\ Bezymyannyy $^{3}$, and Valentin Silyanov ${ }^{1}$ \\ ${ }^{1}$ Moscow Automobile and Road Construction State Technical University (MADI), 125319 Moscow, \\ Russia \\ ${ }^{2}$ Mevotech, ON, L4V 1L5 Toronto, Canada \\ ${ }^{3}$ EKF Electrotechnica LLC, 127273 Moscow, Russia
}

\begin{abstract}
This paper addresses the analytical questions surrounding the index of customers satisfaction level, and their differentiation into unit clusters in the light weight and passenger vehicles market.
\end{abstract}

\section{Introduction}

The purpose of this study as carried out by the Department of Road Transport Operations, Moscow State Automobile and Road Technical University (MADI), is to propose a set of principles, approaches and the basic methodological provisions directed towards the development, and practical implementation of tasks, aimed at solving the problems of assessment, forecasting, and optimizing the functioning of the inventory management systems of spare parts and materials in its specified area of business activity.

\section{Material and methods}

The practical implementation of the above-mentioned requires an intensive study, and the solving of the following sequentially interrelated set of problems:

- carry out an analysis ofcustomer's satisfaction level index $(U)$ (vehicle owners), and differentiate the highest satisfaction levels index into clusters in the light duty and passenger vehicle market (hereinafter referred to as "light weight vehicles" - LWV);

- identify sales dynamics history of LWV, followed with subsequent modeling of sales forecast, both for all of the LWV brands introducedinto the Russian market, as well as the clusters with the largest consumer satisfaction index, followed by an assessment of the correlation between sales volumes and changes in economic situations;

- highlighting the most represented brands of LWV, with the highest index of customer satisfaction, and a non reducible dynamics of volume introduced into the market for this type of vehicle group.

\footnotetext{
*Corresponding author: solntsev@madi.ru
} 
- with the aim of solving the problems of assessment, forecasting, and optimizing the functioning of the Inventory Management Systems (IMS) of spare parts and materials in its specified area of business activity, there is need for solving some set of problems focused on the following:

- distinguish the make and models from previously formed clusters of represented makes of LWV and the identification of critical elements based on the level of efficiency and reliability which are subject to further analysis aimed at solving the problems of forecasting, and optimizing the functioning of the IMS;

- obtaining, processing and conducting an analysis of the represented information on the dynamic intensity of the operation and the operational reliability index (with the identification of the necessary qualitative and quantitative indicators and parameters), followed by the formation of a failure flow chart of elements (aggregates, nodes, systems, parts) for the selected LWV.

- the development of an inventory management system of spare parts and materials in the specified area of business activity, optimizing and evaluating the operational efficiency for the selected elements and make of the LWV, taking into consideration the dynamics of introduction into the market, and the forecasted trends in economic conjuncture;

- develop the functioning dynamic control principles of the IMS based on a group of limiting elements of reliability of the LWV for the selected model series of the LWV make under consideration.

Previously conducted studies by experts on issues relating to the modeling, forecasting and management of supplies of spare parts for the effective functioning of the production of technical service and repair (TS and R) of vehicles, considering the forecasting in demand of vehicle services, can be found in [2, 11-17].

Based on the framework of ongoing research and the results obtained, a series of publications is being envisaged on the above-mentioned stages of problem solving.

\section{Theory}

In accordance with the structure of the research presented above, the analysis of vehicle owners preferences introduced into the LWV market with selection of make with the highest level of customer satisfaction index was carried out on the first stage. For this purpose, the statistical information"Rating of the TOP-30 vehicle make with customer satisfaction index"by the analytical agency "AUTOSTAT" [1] was used. The analysis shows that, in general, there is a sufficiently a high customer satisfaction index of vehicles introduced into the LWV market (see fig. 1).

As an evaluation criteria, the following indicators characterizing: the vehicle as a whole; the assembly quality; corrosion resistance; noise insulation; physical appearance / design; the acceleration dynamics; smooth running; control and stability; clearance; ergonomics (comfort and convenience); efficiency of heating systems, ventilation and air conditioning; saloon and luggage compartment capacity; fuel consumption; maintenance cost and repair.

The processing of the above-mentioned information will make it possible in obtaining the following:

- estimation indicators of the level of satisfaction and its fluctuations in the trust and tolerant boundaries;

- plot a distribution pattern;

- highlight the manufacturers - the leaders who are marketing their LWV. 


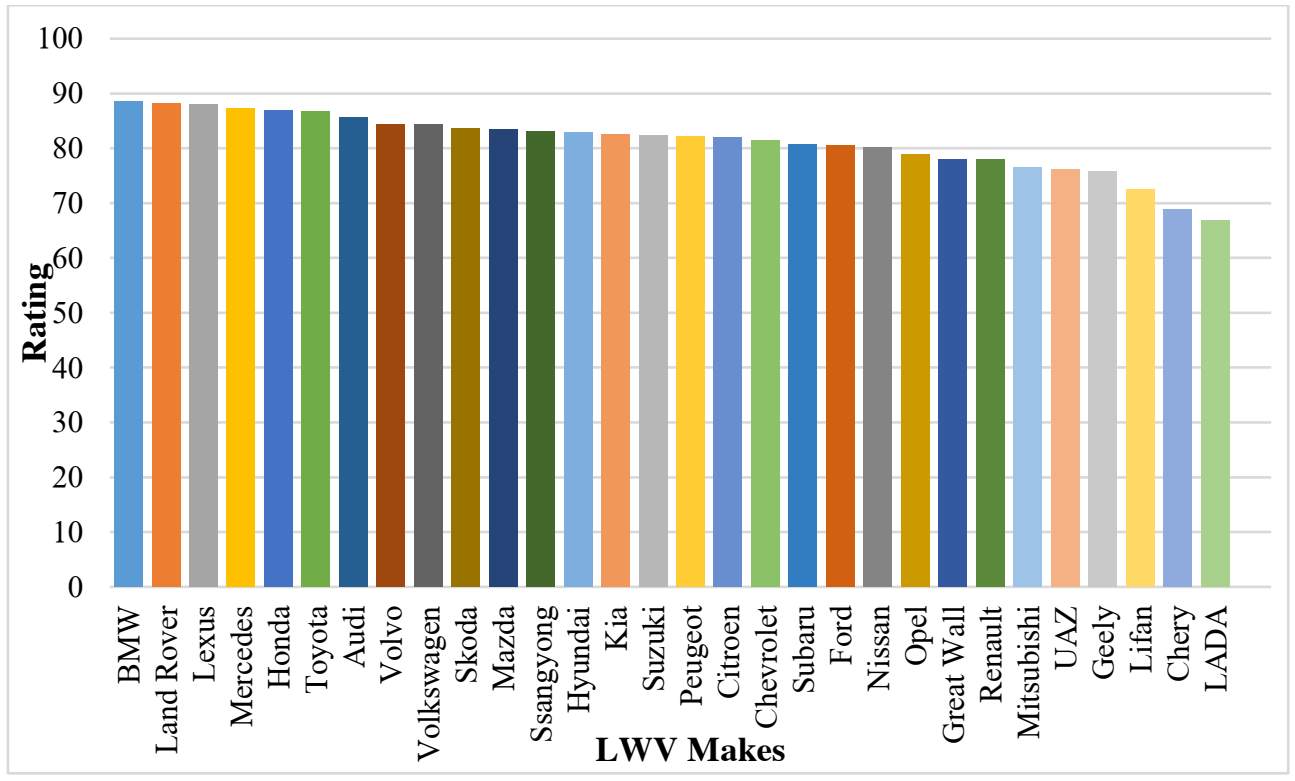

Fig. 1. Satisfaction level of light weight vehicles (LWV). Statistical data from the Rating Agency "AUTOSTAT" - TOP-30.

Figure 2 shows the distribution of the level of satisfaction of LWV from their initial population (see Fig. 1), described by the differential $f(u)$ function of the normal distribution law below:

$$
f(u)=\frac{1}{\sigma(u) \sqrt{ } 2 \pi} e^{-\frac{(U i-\bar{u})^{2}}{2 \sigma^{2}(u)}},
$$

where,

$u$-satisfaction index of the LWV.

Table 1 shows the corresponding estimated statistical indicators of satisfaction level of LWV owners.

Table 1. Satisfaction level of LWV owners

\begin{tabular}{|l|l|l|l|}
\hline S/No & \multicolumn{1}{|c|}{ Indicator } & \multicolumn{1}{|c|}{ Symbol } & Indicator value \\
\hline 1 & $\begin{array}{l}\text { Mean square deviation of the satisfaction } \\
\text { level of the vehicle }\end{array}$ & $\bar{U}$ & 81,213 \\
\hline 2 & $\begin{array}{l}\text { Standard deviation of the satisfaction level of } \\
\text { the vehicle }\end{array}$ & $\sigma(u)$ & 5,42 \\
\hline \multirow{3}{*}{3} & $\begin{array}{l}\text { Indicator control boundaries of satisfaction } \\
\text { level of the vehicle } \\
\text { for } \gamma=0,9\end{array}$ & & \\
$-\begin{array}{l}\text { upper boundary } \\
\text { lower boundary }\end{array}$ & $U_{\gamma}^{b}$ & 88,15 \\
\hline \multirow{3}{*}{4} & $\begin{array}{l}\text { Marginal Sample Mean satisfaction level } \\
\text { relative to its standard deviation for: } \\
+\sigma(u) \text { and }+2 \sigma(u)\end{array}$ & $\bar{U}+\sigma(u)$ & 84,28 \\
\hline
\end{tabular}




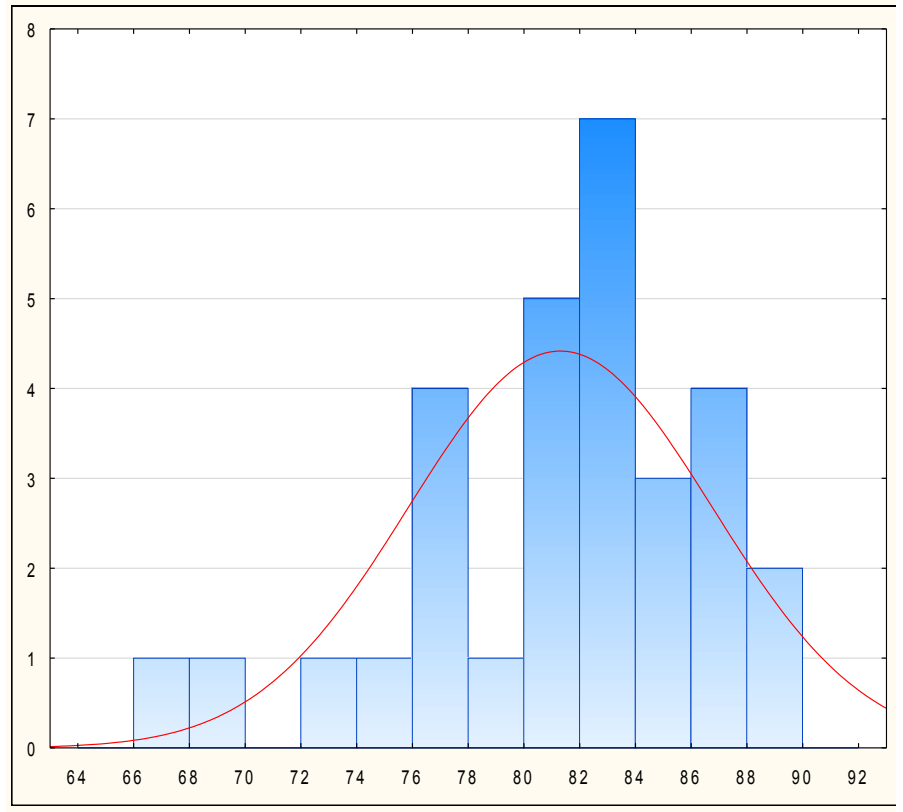

Fig. 2. Differential function of the normal distribution $f(u)$ of the satisfaction level of LWV

The processing of these statistical data was made possible with the use of known mathematical statistics and the theory of probability [3-10].

The analysis of the results presented in fig 1 and 2, as well as table 1 shows that the following LWV falls into the range from $\bar{U}=81,213$ to $\left[\bar{U}+\sigma\left(U_{\text {Audi }}=85,7\right)\right]\left(U_{\text {Audi }}=85,7\right) U_{\text {Audi }}$ : Chevrolet; Citroen; Peugeot; Suzuki; Kia; Hyundai; Ssangyong; Mazda; Skoda; Volkswagen; Volvo; Audi.From the range of $\bar{U}=81,213$ to $[\bar{U}+2 \sigma(u)]=92,053$, in addition to the above listed first-class vehicle make or brand, falls into this category the following LWV: Toyota; Honda; Mercedes; Lexus; Land Rover; BMW.

At same time, within the control boundary for a given probability $\gamma=0,9$ for the range of a satisfaction level index, includes vehicle makes such as Lifan and Lexus (see. fig. 1).

For example, in the first group from $\bar{U}$ to $[\bar{U}+2 \sigma(u)]$, there are such common vehicle make such as Audi $\left(U_{\text {Audi }}=85,7\right)$, which happens to be a direct competitor to makes as BMW, Land Rover, Lexus, Honda, Mercedes, Toyota, Volvo. An estimate of the probability of its belonging to the TOP-30 vehicle makes or brands for the normal distribution law $U$ is determined from the following:

$$
\begin{aligned}
& F(U)=F(Z), \\
& Z_{i}=\frac{U i-\bar{U}}{\sigma(U)},
\end{aligned}
$$

where $F(Z)$ - nominal distribution function;

$Z_{i}$ - nominal random variable for the given index of satisfaction level for the considered LWV.

Audifor example,

$$
Z_{\text {Audi }}=\frac{U_{\text {Audi }}-\bar{U}}{\sigma(U)}=\frac{85,7-81,213}{5,42}=0,828 \text {; }
$$




$$
F\left(U_{\text {Audi }}\right)=F\left(Z_{\text {Audi }}=0,828\right)=0,796 .
$$

The percentage of the above-mentioned LWV makes (BMW, Land Rover, Lexus, Honda, Mercedes, Toyota, Audi, Volvo) from the TOP-30 list is determined using the relationship below (4):

$$
\left[F\left(U_{\max t o p}\right)-F\left(U_{\min t o p}\right)\right] \times 100 \%,
$$

where $\times 100 \%=0,19($ or $19 \%)$ and $F\left(U_{\text {mintop }}\right)$ - assessment of the probability of a TOP-30 LWV with a maximum $U_{\text {maxtop }}$ (equals 88,5 for BMW) and a minimum $U_{\text {mintop }}$ (equals 84,4 for Volvo) level of customer satisfaction.

The probability values $F\left(U_{\max t o p}\right)$ and $F\left(U_{\min t o p}\right)$ are determined from the relationship shown in (2), taking into consideration the normalized random variable in (3).

For $U_{\max t o p}$ and $U_{\min t o p}$ the nominal values $Z_{\max }$ and $Z_{\min }$ are determined as follows:

$$
\begin{aligned}
& Z_{\text {max top }}=\frac{88,5-81,213}{5,42}=1,35 ; \\
& Z_{\text {mintop }}=\frac{84,4-81,213}{5,42}=0,59 .
\end{aligned}
$$

and the probabilities of a LWV falling into the range from $F\left(U_{\max t o p}\right)$ to $F\left(U_{\text {mintop }}\right)$ as defined by formula (2) equals:

$$
\begin{aligned}
& F\left(U_{\text {maxtop }}\right)=F\left(Z_{\text {maxtop }}\right)=1,35=0,912 ; \\
& F\left(U_{\text {mintop }}\right)=F\left(Z_{\text {mintop }}\right)=0,59=0,722 .
\end{aligned}
$$

Thus, the percentage of the following LWV makes or brandsBMW, Land Rover, Lexus, Honda, Mercedes, Toyota, Audi, Volvo in the TOP-30 as calculated using the expression (4) equals:

$$
F\left(U_{\text {mintop }}\right)=F\left(Z_{\text {mintop }}\right) \times 100 \%=0,19(\text { or } 19 \%) .
$$

The graphical representation in the form of satisfaction rating of the above-mentioned LWV makes is shown in fig 3.

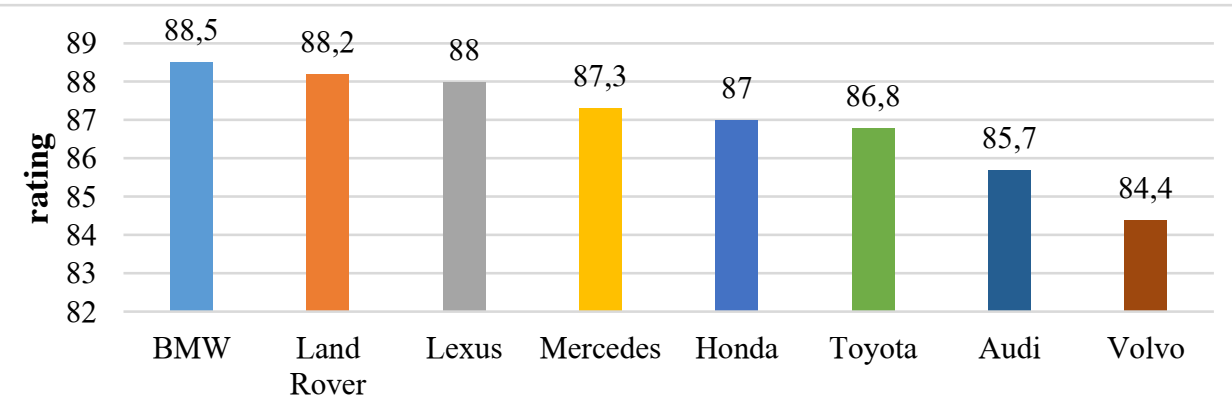

\section{LWV Makes}

Fig. 3. Satisfaction rating distribution of LWV Makes. 


\section{Results}

The analysis presented in Figure 3 helps to provides information on the estimated parameters of the mean square value $\bar{U}^{\sigma p}$ and the mean-square deviation $\sigma\left(\bar{U}^{\sigma p}\right)$ of the satisfaction rating for above-mentioned LWV makes values equalling:

$$
\mathrm{U}^{b r} \geq 84,73 ; \sigma\left(\bar{U}^{b r}\right)=1,377 \text {. }
$$

And as well estimate the lower control boundary $U_{\gamma=0,95}^{b r . n}$ (for the given probability $\gamma=0,95)$ :

$$
U_{\gamma=0,95}^{b r . n .}=\bar{U}^{b r}-Z_{\gamma=0,95} * \sigma\left(\bar{U}^{b r}\right)=86,9875-1,64 * 1,377=84,73
$$

\section{Conclusion}

This ultimately allows the formation of a cluster LWV Makes with $U^{b r} \geq 84,73$ (namely BMW, Land Rover, Lexus, Honda, Mercedes, Toyota, Audi), subject to further analysis in terms of market volume introduction and sales dynamics, by forecasting in the short and medium-term periods, allocation for further consideration of the most represented and critical the level of efficiency and reliability of a vehicle make and their elements (taking into consideration the intensity of operation and operational reliability), followed by the development of an inventory management system for spare parts, its optimization and evaluation of the efficiency of its functioning in its areas of business activity.

The problems as described will be discussed in subsequent series of publications.

\section{References}

1. "AUTOSTAT Analytical Agency» www.autostat.ru., 2016

2. V.A. Zenchenko, D.V. Antonov, Forecasting the Development of the Vehicle Service Market. Methodological Guidelines for Seminars on the "Fundamentals of Marketing in the Vehicle Service Sector".MADI, Moscow, 48 p. (2011)

3. I.I. Eliseeva, V.S. Knyazevskiy, L.I Novorozhkina, Z.A. Morozova, Statistical Theory with the Fundamentals of the Theory of Probabilities, High School Manual, Moscow UNITY-Dana, 446 p. (2001)

4. E.S. Kuznetsov, M.A. Nizov, V.A. Zenchenko. etc., The techniques for determining vehicle reliability indicators when performing comparative operational tests in international freight conditions, Moscow: ASMAP, 200 p. (2002)

5. A.V. Lazarenko, A.N. Moiseev, O.B. Rogova, A.A. Solntsev, Modeling of the dealership network, Automation and control of technical systems, 4.2, P. 8-14 (2013)

6. V.S. Pugachev, The Theory of Probability and Mathematical Statistics, Moscow: Science. The main edition of physics and mathematics, 496 p. (1979)

7. RD 50-690-89 Guidelines. Reliability in technology. The methods for estimating reliability indicators from experimental data. Governmental committee on standards, M., 132 p. (1990)

8. A.N. Rementsov, V.A. Zenchenko, P.B. Fetisov, The mathematical model of defining and planning of spare part consumption. Bulletin of the Moscow State Automobile and Road Technical University (MADI), 3, P. 7-11 (2010)

9. M. Eddous, R. Stansfield, Methods of Decision Making, Trans. with English. Ed. 
Corresponding Member. RAS I.I. Eliseevoy, Moscow: Audit, UNITI, 590 p. (1997)

10. V.M. Trukhanov, Reliability in Technology, M.: Mechanical Engineering, 598 p. (1999)

11. Nikolay Verevkin, Evgeniy Lavrentyev, Igor Chernyaev, Dmitriy Gurin, Method of Providing Safe Technical Condition of Vehicles by Technological Design of Enterprises. Transportation Research Procedia, 20, Pages 665-670 (2017)

12. Alexander Kapustin, Alexey Terentiev, Rational Lifetime of a Vehicle in Terms of Ensuring Security of Its Design. Transportation Research Procedia, 20, Pages 254-260 (2017)

13. Sergey Vorobyov, Igor Chernyaev, Victor Nazarkin, Kirill Filippov, Model of Operation of Motor Vehicles Based on Monitoring of their Performance Characteristics. Transportation Research Procedia, 20, Pages 695-701 (2017)

14. A.E. Chernyshov, V.A. Zenchenko, Forecasting the demand for vehicle services enterprises. Bulletin of the Moscow State Automobile and Road Technical University (MADI), 2, P. 76-82 (2017)

15. G. Yagydaev, A. Nikolaev, V. Stroganov, Efficiency evaluation for the procedures of adaptive testing, Joint International IGIP-SEFI Annual Conference 2010. 19th - 22nd September 2010, Trnava, Slovakia (2010)

16. Andrey B. Nikolaev, Yuliya S. Sapego, Anatolij N. Jakubovich, Leonid I. Berner \& Victor Yu. Stroganov, Fuzzy Algorithm for the Detection of Incidents in the Transport System, International Journal of Environmental and Science Education (IJESE), 11 (16), pp. 9039-9059 (2016)

17. Sultan Zhankaziev, Current Trends of Road-traffic Infrastructure Development, Transportation Research Procedia, 20, Pages 731-739 (2017) 